\title{
Assessment of Safety in COPD Patients Receiving Long Acting $\beta 2$ - agonist in Addition to Long Acting Anticholinergics
}

\author{
Aleena Alex ${ }^{1}$, Dhandapani Chidambaram²*, J Venugopal ${ }^{3}$ and M \\ Mohan $^{4}$ \\ ${ }^{1}$ Department of Pharmacy Practice, KMCH College of Pharmacy, Coimbatore, Tamil \\ Nadu, India \\ ${ }^{2}$ Associate Professor, Department of Pharmacy Practice, KMCH College of Pharmacy, \\ (Affiliated to The Tamil Nadu Dr. M.G.R. Medical University), Coimbatore, Tamil Nadu, \\ India \\ ${ }^{3}$ Department of Pulmonology, KMCH Coimbatore, Tamil Nadu, India \\ ${ }^{4}$ Department of Cardiology, KMCH Coimbatore, Tamil Nadu, India \\ *Corresponding Author: Dhandapani Chidambaram, Associate Professor, Department of \\ Pharmacy Practice, KMCH College of Pharmacy, (Affiliated to The Tamil Nadu Dr. M.G.R. \\ Medical University), Coimbatore, Tamil Nadu, India.
}

\begin{abstract}
Background: Chronic obstructive pulmonary disease (COPD) is characterized by progressive airflow constraint and is highly prevalent disease which may cause functional disability. The use of dual bronchodilator plays major role in the management of chronic obstructive pulmonary disease. Both short acting and long acting bronchodilator combinations are very effective for moderate to severe COPD. Cardiovascular changes in patients with chronic obstructive pulmonary disease (COPD) with the use of these combination drugs are important for improving treatment decisions.

Objectives: To check the cardiovascular risk and safety of using combination therapy with long acting $\beta 2$ - agonist and long acting anticholinergics in COPD patients. To evaluate the adherence while using inhaler and educate about inhaler technique.

Method: It is a prospective observational study, patients aged more than 18 years who were diagnosed with COPD and those who received inhalation therapy included glycopyrronium and indacaterol included in the study.

Results: A total of 50 patients included in the study. The main parameters were monitored included ECG, Heart rate, Blood pressure. The patient's blood pressure level mainly in the prehypertensive level. By considering the heart rate level of patient variation of heart rate in each visit can be seen. The comparison of each visits shows the significant changes for the heart rate variation. Out of 50 patients majority of patients are having abnormal ECG (88\%). The main abnormality found in the ECG findings was sinus tachycardia (26\%). The adherence of patients during each visit by showing the video of inhaler technique, among 50 patients 44 were counseled by video demonstration and rest of 6 patients by orally. The improvement of patients adherence level by showing the significant value (0.000).

Conclusion: The cardiovascular safety of this combination drug is harmless to an extent. The changes in blood pressure, heart rate and ECG is appear to safely tolerated and slight changes in these parameters are due to weakness and the effect of the drug in related to the response of patient's different body characteristics. Proper inhalation technique gives the patients to take the inhaler confidently by knowing the better way of its usage.
\end{abstract}

Keywords: COPD; Bronchodilator; Inhalers; Combination Drug; ECG

\section{Introduction}

Chronic obstructive pulmonary disease (COPD), a largely preventable and manageable respiratory condition, affects more than 1 in 4 adults older than 35 years, is the third leading cause of death in the United States, and is a leading cause of hospitalization for chronic disease [1].
Chronic obstructive pulmonary disease (COPD) is characterized by progressive airflow limitation and is a leading cause of morbidity and mortality worldwide that causes a significant burden on society. It is the fourth leading cause of death and is projected to be the world's third leading cause of mortality by 2020 . The Global Initiative for Chronic Obstructive Lung Disease (GOLD) guidelines 
recommends the use of one or more bronchodilators as maintenance therapy for the treatment and management of COPD [2].

According to World Health Organization estimates, 65 million citizens have moderate to severe COPD. More than 3 million people died of COPD in 2005 corresponding to $5 \%$ of all deaths globally and it is expected to be the third leading cause of death by 2030 . Most of the information presented on COPD prevalence, morbidity and mortality comes from high-income countries. Even in those countries, accurate epidemiologic data on COPD are difficult and expensive to collect. However, it is known that low- and middleincome countries by now shoulder much of the burden of COPD with almost $90 \%$ of COPD deaths taking place in these countries. In India non-communicable diseases (NCD) were estimated to have accounted for $53 \%$ of all deaths and $44 \%$ of disability adjusted life years (DALYs) lost in 2005. Of these chronic respiratory disease accounted for 7\% deaths and 3\% DALYs lost India also has had the ignominy of experiencing the "highest loss in potentially productive years of life worldwide in 2005. Crude estimates recommend there are 30 million COPD patients in India. India contributes a major and growing percentage of COPD mortality which is estimated to be amongst the highest in the world; i.e. more than 64.7 estimated age standardized death rate per 100,000 amongst both sexes [3].

Of all chronic respiratory diseases, chronic obstructive pulmonary disease (COPD) and asthma are the most common. These diseases ranked among the top 20 conditions causing disability globally and were ranked eighth (COPD) and $23^{\text {rd }}$ (asthma) as causes of disease burden as calculated by disability-adjusted life years (DALYs) in 2015. Both death rates and prevalence of COPD steeply increase with age. Spirometry is the fundamental tool used to define and stage COPD and accordingly, establish population prevalence in surveys [4].

Bronchodilators are vital to the pharmacological management of chronic obstructive pulmonary disease (COPD). The efficacy and safety of glycopyrronium and indacaterol, given as long-acting bronchodilator monotherapies in patients with moderate-tosevere COPD, has been demonstrated in several Phase III studies. In patients whose symptoms are insufficiently controlled by bronchodilator monotherapy, the Global initiative for chronic Obstructive Lung Disease (GOLD) strategy for the management of COPD recommends the addition of a second bronchodilator; this is supported by evidence showing that the addition of a second bronchodilator from a different pharmacological class improves lung function, symptoms, and health status compared with monotherapy, without significantly increasing the risk of side effects [5].

COPD is often associated with several other co morbidities, mainly affecting the cardiovascular (CV) system, such as ischemic heart disease, heart failure and arrhythmias, cerebrovascular disease, and peripheral artery disease. Concomitant heart failure is an independent predictor of mortality in patients with COPD exacerbations [4], given the strong relationship between heart and lung. Pharmacological strategies in COPD patients aim to decrease the number and frequency of exacerbations and improve symptom control and exercise tolerance [6].

In the pivotal Phase III Indacaterol and Glycopyrronium bromide clinical studies (IGNITE) clinical trial programme, QVA149 o.d. demonstrated an acceptable safety profile, with adverse events (AEs) and serious AEs (SAEs) being similar to placebo, its monocomponents, tiotropium or salmeterol/fluticasone combination (SFC) [7].

Therapeutic choice always depends on the evaluation of biological characteristics of the disease, symptoms, previous therapies and responses to them, health status and last but not least patient preference. Therefore, the best possible therapy is the one drawn on the medical history of each patient. However, results from clinical trials, clinical practice, and guidelines are important for an evidence-based medicine approach [8].

\begin{tabular}{|c|c|c|c|}
\hline Classes & $\begin{array}{l}\text { Dosage Forms } \\
\text { and Strengths }\end{array}$ & $\begin{array}{l}\text { Adverse } \\
\text { Effects }\end{array}$ & Pharmacology \\
\hline \begin{tabular}{|l} 
Anticholin- \\
ergics \\
Beta two \\
agonist \\
combination
\end{tabular} & $\begin{array}{l}\text { Adult inhalation } \\
\text { powder }(27.5 \\
\text { mcg/15.6mcg)/ } \\
\text { capsule }\end{array}$ & \begin{tabular}{|} 
Nasopharyngi- \\
tis $(4.1 \%)$ \\
Hypertension \\
$(2 \%)$ \\
Back pain \\
$(1.8 \%)$ \\
Oropharyngeal \\
pain $(1.6 \%)$ \\
Post marketing \\
Reports \\
Angioedema \\
Dysphonia
\end{tabular} & $\begin{array}{c}\text { Glycopyrronium: } \\
\text { Long-acting mus- } \\
\text { carinic antagonist } \\
\text { (LAMA); often } \\
\text { referred to as an } \\
\text { anticholinergic; } \\
\text { produces broncho- } \\
\text { dilation by inhibit- } \\
\text { ing acetylcholine } \\
\text { effect on musca- } \\
\text { rinic receptors in } \\
\text { the airway smooth } \\
\text { muscle. } \\
\text { Indacaterol: } \\
\text { Long-acting } \\
\text { beta2-agonist } \\
\text { (LABA); stimu- } \\
\text { lates intracellular } \\
\text { adenyl cyclase, } \\
\text { causing conversion } \\
\text { of ATP to cyclic } \\
\text { AMP; increased } \\
\text { cyclic AMP levels } \\
\text { cause relaxation of } \\
\text { bronchial smooth } \\
\text { muscle }\end{array}$ \\
\hline
\end{tabular}

Table 1: Indacaterol, inhaled/glycopyrrolate inhaled [9]. 


\begin{tabular}{|c|c|c|c|c|}
\hline \multirow[t]{2}{*}{ Indacaterol } & Absorption & Distribution & Metabolism & Elimination \\
\hline & $\begin{array}{l}\text { Absolute bioavailabil- } \\
\text { ity: } 43-45 \% \\
\text { Peak plasma time: } 15 \\
\text { min }\end{array}$ & $\begin{array}{l}\text { Protein bound: } \\
\text { 95\% } \\
\text { Vd: } 2361-2557 \mathrm{~L}\end{array}$ & $\begin{array}{l}\text { Metabolized by UGT1A to the phenolic } \\
\text { O-glucuronide } \\
\text { Also undergoes hydroxylation (predomi- } \\
\text { nantly by CYP3A4) }\end{array}$ & $\begin{array}{l}\text { Half-life: } 40-56 \mathrm{hr} \\
\text { Renal clearance: } \mathrm{L} / \mathrm{hr} \\
\text { - Systemic clearance: } 18.8 \text { - 23.3 L/hr } \\
\text { Excretion } 54 \% 0 \text { (unchanged) and } \\
23 \% \text { (metabolites) in feces }\end{array}$ \\
\hline $\begin{array}{l}\text { Glycopyrro- } \\
\text { nium }\end{array}$ & $\begin{array}{l}\text { Peak plasma time: } 5 \\
\text { minutes }\end{array}$ & $\begin{array}{l}\text { Vd: } 83 \text { - } 376 \mathrm{~L} \\
\text { Protein bound: } 38 \\
-41 \%\end{array}$ & $\begin{array}{l}\text { Hydroxylation of results in a variety of } \\
\text { mono-and bishydroxylated metabolites } \\
\text { and direct hydrolysis results in the for- } \\
\text { mation of a carboxylic acid derivative }\end{array}$ & $\begin{array}{l}\text { Half-life: } 33 \text { - 53hr } \\
\text { Excretion } 60 \text { - } 70 \% \text { urine: } 30-40 \% \\
\text { nonrenal (mostly } \\
\text { by metabolism; also biliary) }\end{array}$ \\
\hline
\end{tabular}

Table 2: Pharmacokinetics properties [9].

\begin{tabular}{|c|c|c|}
\hline $\begin{array}{l}\text { Chemical } \\
\text { Name }\end{array}$ & Indacaterol Maleate & Glycopyrronium bromide \\
\hline Chemical name & $\begin{array}{l}\text { (R)-5-[2-(5,6-Diethylindan-2-ylamino)-1- } \\
\text { hydroxyethyl]-8-hydroxy-1H-quinolin-2-one maleate }\end{array}$ & $\begin{array}{l}\text { 3-(2-Cyclopentyl-2-hydroxy-2- } \\
\text { phenylacetoxy)- 1,1- } \\
\text { dimethylpyrrolidinium bromide }\end{array}$ \\
\hline $\begin{array}{l}\text { Molecular } \\
\text { formula and } \\
\text { molecular mass }\end{array}$ & $\mathrm{C}_{24} \mathrm{H}_{28} \mathrm{~N}_{2} \mathrm{O}_{3} \cdot \mathrm{C}_{4} \mathrm{H}_{4} \mathrm{O}_{4}(508.56)$ & $\mathrm{C}_{19} \mathrm{H}_{28} \mathrm{NO}_{3} \mathrm{Br}$ Salt form on anhydrous basis: 398.33 \\
\hline $\begin{array}{l}\text { Structural } \\
\text { formula }\end{array}$ & $\mathrm{HOOC}_{\mathrm{COOH}}^{\mathrm{H}}$ & $\mathrm{H}_{3} \mathrm{C}_{\mathrm{Br}^{-}}$ \\
\hline $\begin{array}{l}\text { Physicochemi- } \\
\text { cal properties }\end{array}$ & $\begin{array}{l}\text { - } \begin{array}{l}\text { Pure R-enantiomer } \\
\text { - }\end{array} \text { The pH of indacaterol maleate in } 0.1 \%(\mathrm{~g} / 100 \mathrm{ml}) \text { suspen- } \\
\text { sion in water at room temperature is } 4.9 \text {. The } \mathrm{pH} \text { value of } \\
0.1 \%(\mathrm{~g} / 100 \mathrm{ml} \text { ) solution in water/ethanol } 80: 20(\mathrm{~V} / \mathrm{V}) \text { at } \\
\text { room temperature is } 5.0 \text {. } \\
\text { The melting range of indacaterol is } 195-202^{\circ} \mathrm{C} \text { with decom- } \\
\text { position. } \\
\text { Indacaterol maleate is a white to very slightly grayish or } \\
\text { very slightly yellowish powder. Indacaterol maleate is freely } \\
\text { soluble in N-methyl pyrrolidone and dimethylformamide, } \\
\text { slightly soluble in methanol, ethanol, propylene glycol and } \\
\text { polyethylene glycol } 400 \text {, very slightly soluble in water, iso- } \\
\text { propyl alcohol and practically insoluble in } 0.9 \% \text { sodium } \\
\text { chloride in water, ethyl acetate and n-octanol. }\end{array}$ & $\begin{array}{l}\text { - The drug substance glycopyrronium bromide } \\
\text { presents } 2 \text { asymmetric carbon atoms and is an } \\
\text { optically inactive racemic mixture of } 2 \text { stereoiso- } \\
\text { mer's }(2 \mathrm{~S}, 3 \mathrm{R} \text { and } 2 \mathrm{R}, 3 \mathrm{~S}) \text {, hereafter referred to } \\
\text { as the stereoisomers (S, R) and }(\mathrm{R}, \mathrm{S}) \text {. } \\
\text { - The pH of glycopyrronium bromide in } 1.0 \% \mathrm{~m} / \mathrm{V} \\
\text { (g/100 } \mathrm{mL} \text { ) solution in water at room tempera- } \\
\text { ture is } 6.0 \text {. } \\
\text { - Melting range: } 193-198{ }^{\circ} \mathrm{C} \\
\text { - } \\
\text { Glycopyrronium bromide is a white to practically } \\
\text { white powder. Glycopyrronium bromide is freely } \\
\text { soluble in water, } 0.9 \% \text { sodium chloride in water, } \\
\text { methanol, and ethanol (50\% and } 95 \%) \text {. }\end{array}$ \\
\hline $\begin{array}{l}\text { Indacaterol } \\
\text { glycopyrro- } \\
\text { nium inhaled }\end{array}$ & & \\
\hline
\end{tabular}

Table 3: Pharmaceutical information [10]. 
Cardiovascular changes with indacaterol/glycopyrronium inhaled

The combination of a long-acting beta ${ }_{2}$-agonist (indacaterol) and a long-acting muscarinic antagonist (glycopyrronium). Cardiovascular effects, such as cardiac arrhythmias, e.g. atrial fibrillation and tachycardia, may be seen after the administration of sympathomimetic agents and muscarinic receptor antagonists, including breezhaler. In case such effects occur, treatment may have to be discontinued.

Cardiovascular effects such as tachycardia, arrhythmia, palpitations, myocardial ischemia, angina pectoris, hypertension or hypotension have been associated with use of with beta-adrenergic agonists. In addition, beta-adrenergic agonists have been reported to generate electrocardiogram (ECG) changes, such as flattening of the T wave, prolongation of the QTc interval, and ST segment depression. Therefore, this inhaler like all products containing betaadrenergic agonists should be used with caution in patients with cardiovascular disorders, especially coronary insufficiency, acute myocardial infarction, cardiac arrhythmias, and hypertension.

\section{Heart rate}

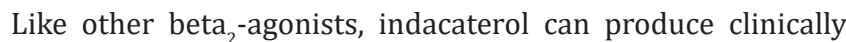
significant cardiovascular effects in some patients as measured by an increase in pulse rate, systolic or diastolic blood pressure or cardiac arrhythmias such as supraventricular tachycardia and extra systoles. If such effects occur, the use of it may need to be discontinued.

\section{QT Interval}

Like other beta ${ }_{2}$-agonists, caution is recommended if indacaterol/glycopyrronium is administered to patients with a known history of QTc prolongation, risk factors for torsade de pointes (e.g. hypokalemia), or patients who are taking medications known to prolong the QTc interval [10].

\section{Materials and Methods}

This is a prospective observational study. The study conducted at KMCH Coimbatore and the data obtained from the patient medication chart and patient counseling. The duration of study is six months. The patients included criteria; Patients aged $>18$ years; patients who were diagnosed with COPD, Patients who received inhalation therapy included glycopyrronium and indacaterol. Exclusion criteria: Patients who were allergic to glycopyrronium and indacaterol inhalation or any other inhaled ingredients, Patients who were not take ECG in the first and third month. All the patient coming under inclusion criteria were taken as study population. And 50 patients is the number of samples to be included in the study. During the study patient's heart rate, blood pressure and ECG were monitored and also evaluated the adherence while using this combination inhaler.

\section{Statistical analysis}

Data is going to be collected from 50 patients who are coming to hospital for the treatment of COPD. Using various parameter the efficacy of the drugs which is given in the combination are calculated using SPSS (Statistical package for social science) software version 20, ANOVA.

\section{Results}

The prospective observational study was aimed to assess the cardiovascular safety of long acting beta two agonist in addition to long acting anticholinergics in COPD patients. During the study period, a total of 50 COPD patients visited the out-patient and inpatient pulmonology department of the hospital.

\section{Demographic results}

Results from the table showed that the among 50 patients $40 \%$ were in the age group of 61 - 70 years and $26 \%$ were in age group of 71 - 80 years. 22\% were in age group of 51 - 60 years and $6 \%$ were in age group 31 - 40 and 41 - 50. Among 50 patients $74 \%$ were male and $26 \%$ were female. From the 50 patients $34 \%$ of patients are jobless and $30 \%$ of patients were farmers. Among 50 patients $40 \%$ were of them having family history of COPD whereas $60 \%$ of not having family history of COPD. Out of 50 patients $50 \%$ were exsmokers and $34 \%$ were non-smokers and $16 \%$ were current smokers. By considering the past history of diabetes mellitus, Most of the patients were non-diabetic (74\%) and 26\% were diabetic.

\section{Experimental results}

When looking to the blood pressure level, systolic blood pressure value in each visit remains in the prehypertensive range (120 - $139 \mathrm{mmHg}$ ) but in case of diastolic pressure value in the normal range $(<80 \mathrm{mmHg})$. The p value by comparing the systolic BP with visit one, two and three is found to be significant $(\mathrm{p}<0.05)$ is 0.001 , 0.006 and 0.008 respectively for systolic BP. In case of diastolic BP, $0.008,0.033$ and 0.020 and are also found to be significant.

By checking the 50 patients, heart rate remains normal in most of the patients. In the first visit $42 \%$ were in the normal HR level but $5 \%$ were tachycardia and $3 \%$ were in decreased level of pulse rate. In the second visit, $56 \%$ of patients were having normal pulse rate and $44 \%$ were in high pulse rate. In the third visit $58 \%$ were in the normal and $38 \%$ were having high pulse rate. The comparison of heart rate with visit one and two visits gives significant value such as 0.003 and 0.015 .

When we analyzed the FEV1 (Forced Expiratory Volume in one second) during the first visit $66 \%$ of patients were found to be severe level of COPD and $28 \%$ were very severe level of COPD and $6 \%$ were moderate condition. When we gone to second visit $76 \%$ of patients were in moderate level because of the improvement in the condition due to the treatment. Whereas $18 \%$ of patients are in 
severe and 6\% were in very severe condition. The comparison of both visits shows significant result by giving the $\mathrm{p}$ value of 0.000 .

The level of potassium during the first visit $92 \%$ of the patients were in the normal range and $4 \%$ of patients were in hyperkalemia and $4 \%$ not responded to the study. In the second visit $50 \%$ of the patients in the normal potassium level and $30 \%$ of patients are in increased level of potassium and $16 \%$ are under the level. By checking the $\mathrm{p}$ value of both visits is 0.000 and is found to be significant.

By considering the Fasting Blood Sugar (FBS) 54\% of patients are in the normal status and $28 \%$ were in hyperglycemic condition during the first visit. In the second visit, only $24 \%$ of patients having normal FBS value and $70 \%$ of patients were hyperglycemic condition and $6 \%$ not responded. The p value obtained by comparing the both visit is 0.202 and is not significant.

Among 50 patients in the first visit, $54 \%$ of patients were having normal level of Random Blood Glucose (RBG) and 42\% were having increased level of RBS and 4\% of patients didn't responded. In the next visit, $16 \%$ were in the normal level and $80 \%$ of patients were in the increased level of RBG and 4\% didn't responded. The $p$ value of this 0.000 is found to be significant.

Out of the 50 patients $88 \%$ were found to be abnormal ECG during the first visit and only $12 \%$ were normal. In the second visit $92 \%$ of patients were found to be abnormal ECG and $8 \%$ were in the normal. The abnormalities are sinus tachycardia, RVH (Right ventricular hypertrophy), Normal systolic with grade 1 diastolic dysfunction, MMR (Mild mitral regurgitation), PAH (Pulmonary artery hypertension), Bradycardia, Right atrial pressure. The result is found to be not significant by comparing the both visits 0.159 .

In the first visit of morisky adherence (Do you ever forget to take your medicine?) $74 \%$ of patients responded "yes" and $26 \%$ were "no" to the first question. In the second visit of the same question 68\% were responded 'no' and 32\% were 'yes' to the same. By comparing the both visits of this question was found to be significant 0.000 . In the first visit of second question (Are you careless at times about taking your medicine?) 66\% were responded 'no' and $34 \%$ were 'yes' to the question. In the second visit 92\% were 'no' and $8 \%$ were 'yes' to the query. The result by comparing the question for both visit found to be significant (0.001). In the first visit 'When you feel better do you sometimes stop taking your medicine' (third question) 68\% were responded 'no' and 32\% were 'yes' in the response. In the second visit 96\% responded 'no' and $4 \%$ 'yes' to the question. The comparison of both visit for this question is found to be significant (0.000). In the first visit of fourth question (Sometimes you felt worse, when you take the medicine, do you stop taking it?) 48\% responded 'no' and 52\% were 'yes'. And in the second visit of the same 78\% were responded 'no' and $22 \%$ responded 'yes' to the question. The response of patient by comparing the both visit is found to be significant (0.001). During the time of first visit, $62 \%$ of patient's shows medium adherence and $30 \%$ showed low and only $8 \%$ of patients showed the high adherence. The total score of both visits is significant 0.000 .

Out of 50 patients, 44 patients are counseled by showing the video of inhaler technique rest of 6 patients are counseled by orally. But in the second visit, $48 \%$ of patients shows high adherence and $46 \%$ in the medium and only $6 \%$ of patients shows low adherence.

By considering the gender dependent variability in heart rate, males have higher heart rate when compared to female patients. In the first visit out of 37 males, 31 male patients are having normal range of heart rate and the second visit 22 male patients are under control In the third visit 21 males are in the normal heart rate.

(Table 4, figure 1-3, table 5, figure 4 , table 6 , figure 5 , table 7 , figure 6 , table 8 , figure 7 , table 9 , figure 8 , table 10 , figure 9 , table 11 , figure 10 , table 12 , figure 11,12 )

\section{Discussion}

Chronic Obstructive Pulmonary Disease is a group of lung diseases that block airflow and make it difficult to breath. Emphysema and chronic bronchitis are the most common conditions that make COPD. Damage to the lungs from COPD can't be reversed.

In this study more number of males (74\%) than females (26\%) with COPD with the mean age of 63.7 years and it is found matching with the study by Van de Mele B., et al. (2010) a randomized study which includes the mean age of all patients was 63.8 years and the majority of patients were male (76.5\%) and Caucasian (98.8\%) [3].

COPD does seem to run in families. If parents had chest problems then the risk is higher. In this study $40 \%$ of patients are having family history of COPD. Craig P Hersh., et al. (2014) had done a study which somewhat similar to this study, Family history of COPD is a strong risk factor for COPD. Parental history of COPD may contribute to nearly $20 \%$ of the risk of COPD in the population. Subjects with a parental history of COPD had more severe disease,

\begin{tabular}{|l|c|c|}
\hline Past Medical History-DM & Frequency & Percentage (\%) \\
\hline Yes & 13 & 26.0 \\
\hline No & 37 & 74.0 \\
\hline Total & 50 & 100.0 \\
\hline
\end{tabular}

Table 4: Distribution of patients according to their past medical history of diabetes mellitus $(n=50)$. 


\begin{tabular}{|c|c|c|c|c|c|c|}
\hline \multirow{2}{*}{$\begin{array}{l}\text { Heart rate } \\
\text { (bpm) }\end{array}$} & \multicolumn{2}{|c|}{ Visit 1} & \multicolumn{2}{|c|}{ Visit 2} & \multicolumn{2}{|c|}{ Visit 3} \\
\hline & Frequency & Percentage (\%) & Frequency & Percentage (\%) & Frequency & Percentage (\%) \\
\hline$<60$ & 3 & 6.0 & - & - & 2 & 4.0 \\
\hline $60-100$ & 42 & 84.0 & 28 & 56.0 & 29 & 58.0 \\
\hline$>100$ & 5 & 10.0 & 22 & 44.0 & 19 & 38.0 \\
\hline Total & 50 & 100.0 & 50 & 100.0 & 50 & 100.0 \\
\hline $\mathrm{p}$-value & \multicolumn{2}{|c|}{${ }^{*} 0.003$} & \multicolumn{2}{|c|}{ *0.015 } & \multicolumn{2}{|c|}{0.123} \\
\hline
\end{tabular}

Table 5: Distribution of patients according to the heart rate $(n=50)$. $p$-value $<0.05$ considered as statistically significant.

\begin{tabular}{|c|c|c|c|c|c|}
\hline \multirow{2}{*}{ FEV1 (\%) } & \multicolumn{2}{|c|}{ Visit 1} & \multicolumn{2}{|c|}{ Visit 2} & \multirow{2}{*}{ p-value } \\
\hline & Frequency & Percentage (\%) & Frequency & Percentage (\%) & \\
\hline$<30$ & 14 & 28.0 & 3 & 6.0 & \multirow{5}{*}{${ }^{*} 0.000$} \\
\hline $30-50$ & 33 & 66.0 & 9 & 18.0 & \\
\hline $50-80$ & 3 & 6.0 & 38 & 76.0 & \\
\hline Total & 50 & 100.0 & 50 & 100.0 & \\
\hline Mean \pm SD & \multicolumn{2}{|c|}{$1.78 \pm 0.545$} & \multicolumn{2}{|c|}{$2.70 \pm 0.580$} & \\
\hline
\end{tabular}

Table 6: Distribution of patients according to the forced expiratory volume in one second $(n=50)$. p-value $<0.05$ considered as statistically significant.

\begin{tabular}{|c|c|c|c|c|c|}
\hline \multirow{2}{*}{$\begin{array}{c}\text { Potassium } \\
\text { (mEq/L) }\end{array}$} & \multicolumn{2}{|c|}{ Visit 1} & \multicolumn{2}{|c|}{ Visit 2} & \multirow{2}{*}{ p-value } \\
\hline & Frequency & Percentage (\%) & Frequency & Percentage (\%) & \\
\hline Not Taken & 2 & 4.0 & 2 & 4.0 & \multirow{6}{*}{$* 0.000$} \\
\hline $3.5-5$ & 46 & 92.0 & 25 & 50.0 & \\
\hline$<3.5$ & - & - & 8 & 16.0 & \\
\hline$>5$ & 2 & 4.0 & 15 & 30.0 & \\
\hline Total & 50 & 100.0 & 50 & 100.0 & \\
\hline Mean \pm SD & \multicolumn{2}{|c|}{$1.04 \pm 0.450$} & \multicolumn{2}{|c|}{$1.72 \pm 0.948$} & \\
\hline
\end{tabular}

Table 7: Distribution of patients according to the level of potassium $(n=50)$. $p$-value $<0.05$ considered as statistically significant.

\begin{tabular}{|c|c|c|c|c|c|}
\hline \multirow{2}{*}{$\begin{array}{c}\text { FBS } \\
(\mathrm{mg} / \mathrm{dL})\end{array}$} & \multicolumn{2}{|c|}{ Visit 1} & \multicolumn{2}{|c|}{ Visit 2} & \multirow{2}{*}{ p-value } \\
\hline & Frequency & Percentage (\%) & Frequency & Percentage (\%) & \\
\hline Not Taken & 9 & 18.0 & 3 & 6.0 & \multirow{5}{*}{0.202} \\
\hline$>100$ & 14 & 28.0 & 35 & 70.0 & \\
\hline $60-100$ & 27 & 54.0 & 12 & 24.0 & \\
\hline Total & 50 & 100.0 & 50 & 100.0 & \\
\hline Mean \pm SD & \multicolumn{2}{|c|}{$1.36 \pm 0.776$} & \multicolumn{2}{|c|}{$1.18 \pm 0.523$} & \\
\hline
\end{tabular}

Table 8: Distribution of patients according to the level of fasting blood sugar ( $n=50)$. $p$-value $<0.05$ considered as statistically significant.

\begin{tabular}{|c|c|c|c|c|c|}
\hline \multirow{2}{*}{ RBG (mg/dL) } & \multicolumn{2}{|c|}{ Visit 1} & \multicolumn{2}{|c|}{ Visit 2} & \multirow{2}{*}{ p-value } \\
\hline & Frequency & Percentage (\%) & Frequency & Percentage (\%) & \\
\hline Not Taken & 2 & 4.0 & 2 & 4.0 & \multirow{5}{*}{$* 0.000$} \\
\hline$>125$ & 21 & 42.0 & 40 & 80.0 & \\
\hline $75-125$ & 27 & 54.0 & 8 & 16.0 & \\
\hline Total & 50 & 100.0 & 50 & 100.0 & \\
\hline Mean \pm SD & \multicolumn{2}{|c|}{$1.50 \pm 0.580$} & \multicolumn{2}{|c|}{$1.12 \pm 0.435$} & \\
\hline
\end{tabular}

Table 9: Distribution of patients according to the level of random blood glucose $(n=50)$.

p-value $<0.05$ considered as statistically significant. 


\begin{tabular}{|c|c|c|c|c|c|}
\hline \multirow{2}{*}{ ECG } & \multicolumn{2}{|c|}{ Visit 1 } & \multicolumn{2}{c|}{ Visit 2 } & \multirow{2}{*}{ p-value } \\
\cline { 2 - 5 } & Frequency & Percentage (\%) & Frequency & Percentage (\%) & \\
\hline Abnormal & 44 & 88.0 & 46 & 92.0 & \multirow{2}{*}{0.159} \\
\cline { 1 - 5 } Normal & 6 & 12.0 & 4 & 100.0 & \\
\hline Total & 50 & 100.0 & 50 & $1.08 \pm 0.274$ \\
\hline Mean \pm SD & \multicolumn{2}{|c|}{$1.12 \pm 0.328$} & \multicolumn{2}{|c|}{} \\
\hline
\end{tabular}

Table 10: Distribution of patients according to the ECG $(n=50)$. p-value $<0.05$ considered as statistically significant.

\begin{tabular}{|c|c|c|c|}
\hline Sl. No. & ECG Findings & Frequency & Percentage (\%) \\
\hline 1 & Sinus tachycardia (ST) & 13 & 26 \\
\hline 2 & RVH (Right ventricular hypertrophy) & 9 & 18 \\
\hline 3 & Normal systolic with grade one diastolic dysfunction & 6 & 12 \\
\hline 4 & Mild Mitral Regurgitation (MMR) & 2 & 4 \\
\hline 5 & Pulmonary Artery Hypertension (PAH) & 4 & 8 \\
\hline 6 & Right Atrial Pressure & 7 & 4 \\
\hline 7 & Sinus tachycardia with RVH & 2 & 2 \\
\hline 8 & Sinus tachycardia with diastolic dysfunction & 1 & 4 \\
\hline 9 & Sinus tachycardia with PAH & 2 & 4 \\
\hline 10 & Sinus tachycardia with Right atrial pressure & 2 & 2 \\
\hline 11 & RVH with MMR & 1 & 2 \\
\hline 12 & RVH with PAH & 1 & \\
\hline
\end{tabular}

Table 11: Distribution of patients according to the ECG abnormalities $(n=50)$.

\begin{tabular}{|c|c|c|c|c|c|}
\hline \multirow{2}{*}{$\begin{array}{c}\text { Category } \\
\text { level }\end{array}$} & \multicolumn{2}{|c|}{ Visit 1} & \multicolumn{2}{|c|}{ Visit 2} & \multirow{2}{*}{ p-value } \\
\hline & Frequency & Percentage (\%) & Frequency & Percentage (\%) & \\
\hline High & 4 & 8.0 & 24 & 48.0 & \multirow{5}{*}{$* 0.000$} \\
\hline Medium & 31 & 62.0 & 23 & 46.0 & \\
\hline Low & 15 & 30.0 & 3 & 6.0 & \\
\hline Total & 50 & 100.0 & 50 & 100.0 & \\
\hline Mean \pm SD & \multicolumn{2}{|c|}{$1.22 \pm 0.582$} & \multicolumn{2}{|c|}{$0.58 \pm 0.609$} & \\
\hline
\end{tabular}

Table 12: Morisky adherence total score $(n=50)$. p-value $<0.05$ considered as statistically significant.

with lower lung function, exercise capacity, and quality of life, and increased dyspnea and COPD exacerbations [29].

Occupational exposure plays a vital role in severity level of COPD. In this study $30 \%$ of patients were farmers and most of the patients were no workers because of their age limitation. The study which promotes the evidence regarding occupational hazard in COPD by Guillien A., et al. (2015), a cross sectional study explains, the prevalence of COPD was higher in agricultural workers (farmers) than in control subjects who had never had any identified occupational exposure. After adjustment for age, sex and to- bacco exposure, the prevalence of COPD was approximately twofold higher in agricultural workers than in non- farming working control subjects, suggesting that agricultural exposure by itself was associated with an increased risk for COPD In addition, our analysis demonstrates that the prevalence of COPD depends not only on the farming activity but also on the region in which farmers work [30].

Smoking is the leading cause of chronic obstructive pulmonary disease (COPD). In this study Ex-smokers are higher (25) and current smokers were 8 . In controversy to this, a study conducted by Hohlfed J M., et al. the number of current smokers (36) were higher 
than ex-smokers (24) [14]. The study conducted by Kim SH., et al. (2017) they found similar result with this study majority of the patients were current smokers (44) followed by ex-smokers (39.8) and nonsmokers (15.8) [37].

COPD may cause high blood pressure in the arteries that causes increased flow of blood to the lungs. This is called pulmonary hypertension. In this study the mean systolic blood pressure was 132 \pm 28.6 and the mean diastolic blood pressure was $82 \pm 16.4$ in this study found to be matched with the study conducted by Spannella F., et al. (2018) the mean systolic blood pressure was $121.6 \pm 24.0$ $\mathrm{mm} \mathrm{Hg}$, the mean diastolic blood pressure was $67.6 \pm 13.4 \mathrm{~mm} \mathrm{Hg}$ [6]. The mean heart rate in this study was $92.6 \pm 12.6$ and when this result compared with the study conducted by Byrd JB., et al. (2018), the mean heart rate was $76 \pm 10$ b.p.m. A linear relationship exists between heart rate and all-cause mortality and cardiovascular events in the population [31].

Forced Expiratory Volume in one second is the amount of air that can force from the lungs in one second. FEV1 is an important tool of evaluating chronic obstructive pulmonary disease and monitoring progression of the condition. The mean post bronchodilator FEV1in both visit study was $46.0 \%$ and the study conducted by Kardos P., et al. (2018) the mean in this post bronchodilator FEV1\% was $~ 58 \%$ across both treatment groups [32].

The serum potassium level is an important marker to prevent future complications because the use of beta-adrenergic agonist and theophylline act to lower potassium level. Hypokalemia in COPD may cause respiratory failure. In this study the level of potassium were normal in the first visit (92\%), during the second visit the patients with normal range of potassium were $50 \%$ and in some patients the level become decreased (16\%) remaining $30 \%$ having hyperkalemia (> $5 \mathrm{mEq} / \mathrm{L}$ ). The study conducted by Buhl R., et al. (2011) Safety and tolerability were assessed by adverse events and the incidence of notable values for vital signs, Frederica's correction of QT interval (QTc interval) measured from ECGs, reduced levels of serum potassium $\left(<3.0 \mathrm{mmol}-\mathrm{L}^{-1}\right)$ and elevated blood glucose ( $>9.99 \mathrm{mmol}^{-\mathrm{L}^{-1}}$ ). Indacaterol was not found to significantly affect pulse rate, systolic or diastolic blood pressure, corrected QT interval, blood glucose, or serum potassium [33].

Damage to the nervous system weakened respiratory muscles. Glucose level may changes with severity of COPD. In this study $28 \%$ of patients had higher than the normal range of Fasting Blood Sugar ( $>100$ ) and at the second visit increased the number as compared with the previous visit (70\%) of patients. When considering the Random Blood Glucose (RBG) the same result was there. The study conducted by Lehmann S., et al. (2019) in his findings the most frequently reported AEs were dyspnea, deterioration in COPD, nasopharyngitis, oropharyngeal pain, and increase in blood glucose [34].

ECG changes occur in chronic obstructive pulmonary disease (COPD) due to the long term effects of hypoxic-pulmonary vasoconstriction. In this study $88 \%$ of patients had abnormalities in the first visit and $92 \%$ in the next visit. While considering the abnormality of ECG most of the patients are having sinus tachycardia (26\%). The similar result were obtained in the study conducted by Kumar A., et al. (2017) and the result shows that $90 \%$ of patients are having sinus tachycardia [25].

The heart rate variability is due to the autonomic modulation of heart. In this study the when considering the gender dependent variability in heart rate, It shows male patients are having higher than the female patients. This result is matched with the study conducted by Spannella F., et al. (2018) among females; a statistically significant reduction in $\mathrm{HR}$ at T2 versus T0 was documented [6].

The degree to which a patient correctly follows medical advice is the adherence and no adherence to a therapy poses significant barrier to optimal management. In this study the improvement of patients can be seen in the second visit for each level of questionnaire and while checking the total score it shows the progression from the medium (62\%) adherence to high (48\%) adherence level of patients. A similar study related to this result conducted by Abdulsalim S., et al. (2017) explains that, MAQ, which measures adherence through four Yes/No response items, accounts for the various reasons for non-adherence namely: forgetting, carelessness, stopping when feeling better and stopping when feeling worse. [Scoring: - 'YES'=0, 'NO'=1]. Consequently, MAQ scores range between 0 and 4 . It increased from $49 \%$ at the baseline to $80 \%$ after 24 months $(\mathrm{P}<0.001)$. Carelessness about taking medicines was one of the main reasons for non-adherence in COPD patients, but was effectively reduced by the intervention [35].

\section{Conclusion}

Bronchodilators are the first line therapy for chronic obstructive pulmonary disease. The combination therapy of long acting beta two agonist with long acting anticholinergics is considered to be safe and effective through this study.

After the statistical analysis, it is concluded that the patient's blood pressure level mainly in the pre-hypertensive level. By considering the heart rate level of patient variation of heart rate in each visit can be seen. The comparison of each visit shows the significant changes for the heart rate variation. Out of 50 patients majority of patients are having abnormal ECG (88\%). The 
main abnormality found in the ECG findings was sinus tachycardia (26\%). The adherence of patients during each visit by showing the video of inhaler technique, among 50 patients 44 were counseled by video demonstration and rest of 6 patients by orally. The cardiovascular safety of this combination drug is harmless to an extent. The changes in blood pressure, heart rate and ECG is appear to safely tolerated and slight changes in these parameters are due to weakness and the effect of the drug in related to the response of patient's different body characteristics. The efficacy of drug monitored by spirometric evaluation, there obtained a satisfactory data by improvement occurred by comparing the both visits. So that while considering these parameters the combination inhaler is effective and safe. By checking the adherence, the clinical pharmacist can improve the health and functioning by providing good patient counseling. Clinical pharmacist are the upcoming breed of pharmacist in our country. Proper inhalation technique give the patients to take the inhaler confidently by knowing the better way of its usage. The limitations of the study were due to lack of time the patients are not willing to saw the video for inhaler technique. The number of patients was limited due to limited time period. The counselling of patient's was difficult due the availability of proper space.

\section{Acknowledgement}

To acknowledge is known gratitude and gratitude is a valuable duty which ought to pay to valuable people in a lifetime. First and foremost I pay obeisance to the God almighty for blessing me with all the confidence, courage, inspiration and curiosity to complete this project. I take this opportunity to express my gratitude and faithfulness to my esteemed teacher and guide, DR. C. Dhandapani, M. pharm., PhD Associate Professor, Department of Pharmacy Practice, for this remarkable guidance, constant encouragement and constructive comment for the successful completion for this work. I put across my honest thanks and gratitude to my clinical guides Dr. J. Venugopal MD, DNB, EDARM, FCCP (Department Of Pulmonology) and Dr. M. Mohan, MBBS, MD, FSCAI (Department of cardiology) Kovai Medical Center and Hospital, for this guidance, valuable directions and interest shown towards the research work. I owe special thanks to KMCH Ethical Committee for providing permission for doing our project work. I take this opportunity to thank my father Mr. Alexander Joseph, Mother Mrs. Mini Alex, Sister Miss Anitta, who supported and motivated me through all stages. It also gave me great pleasure to dedicate my work to such adorable and affectionate Parents and sister, without whom I wouldn't have been able to reach this stage. For their invaluable affection, concern, encouragement and for the prayers they have offered for the successful completion of my project.

\section{Bibliography}

1. Gershon A., et al. "Cardiovascular Safety of Inhaled Long-Acting Bronchodilators in Individuals with Chronic Obstructive Pulmonary Disease". JAMA Internal Medicine 173.13 (2013): 1175-1184.

2. Maele BV., et al. "Cardiovascular Safety of QVA149, a Combination of Indacaterol and NVA237, in COPD Patients". COPD: Journal of Chronic Obstructive Pulmonary Disease 7 (2010): 418-427.

3. Parvaiz A Koul. "Chronic obstructive pulmonary disease: Indian guidelines and the road ahead". Lung India 30.3 (2013): 175-177.

4. GBD 2015 Mortality and Causes of Death Collaborators. "Global, regional, and national deaths, prevalence, disabilityadjusted life years, and years lived with disability for chronic obstructive pulmonary disease and asthma, 1990-2015: a systematic analysis for the Global Burden of Disease Study 2015 GBD 2015 Chronic Respiratory Disease Collaborators". Lancet Respiratory Medicine 5 (2017): 691-706.

5. Vincken W., et al. "Efficacy and safety of co administration of once-daily indacaterol and glycopyrronium versus indacaterol alone in COPD patients: the GLOW6 study". International Journal of COPD 9 (2014): 215-228.

6. Spannella F., et al. "Combination Therapy of Inhaled Indacaterol/Glycopyrronium for Chronic Obstructive Pulmonary Disease in the Very Elderly: Is It Safe?" An Electrocardiographic Evaluation". Journal of Respiration 95.1 (2018): 22-29.

7. Jadwiga A Wedzicha., et al. "Pooled safety analysis of the fixed-dose combination of indacaterol and glycopyrronium (QVA149), its monocomponents, and tiotropium versus placebo in COPD patients". Respiratory Medicine 108 (2014): 14981507.

8. Rogliani P., et al. "LABA/LAMA fixed-dose combinations in patients with COPD: a systematic review". International Journal of COPD 13 (2018): 3115-3130.

9. Indacaterol, inhaled/glycopyrrolate inhaled (Rx) (2019).

10. Product Monograph: Onbrez Breezhaler. Long-acting beta. Novartis Pharmaceuticals Canada Inc. Montreal, Canada (2015). 
11. Samp J C., et al. "Risk of Cardiovascular and Cerebrovascular Events in COPD Patients Treated With Long-Acting $\beta 2$ Agonist Combined With a Long-Acting Muscarinic or Inhaled Corticosteroid". Annals of Pharmacotherapy (2017): 1-9.

12. Andreas S., et al. "Effect of long-acting $\beta 2$-agonists olodaterol and formoterol on heart rate and blood pressure in chronic obstructive pulmonary disease patients". Pulmonary Pharmacology and Therapeutics 52 (2018): 1-6.

13. Ferguson GT., et al. "Safety of tiotropium/olodaterol in chronic obstructive pulmonary disease: pooled analysis of three large, 52-week, randomized clinical trials". Respiratory Medicine 143 (2018): 67-73.

14. Hohlfeld J M., et al. "Effect of Indacaterol/Glycopyrronium on Pulmonary Perfusion and Ventilation in Hyper inflated COPD Patients (CLAIM): a double-blind, randomized, crossover trial". American Journal of Respiratory and Critical Care Medicine (2018): 1-11.

15. Worth H., et al. "Effect of lung deflation with indacaterol plus glycopyrronium on ventricular filling in patients with hyperinflation and COPD (CLAIM): a double-blind, randomized, crossover, placebo-controlled, single-centre trial". Lancet of respiratory Medicine 105 (2011): 571-579.

16. Kardos P., et al. "Randomized controlled trials and real-world observational studies in evaluating cardiovascular safety of inhaled bronchodilator therapy in COPD". International Journal of COPD 11 (2016): 2885-2895.

17. Calzetta L., et al. "A systematic review with meta-analysis of dual bronchodilation with LAMA/LABA for the treatment of stable chronic obstructive pulmonary disease". Journal of Chest (2016): 1330-1346.

18. Buhl R., et al. "Long-term general and cardiovascular safety of tiotropium/olodaterol in patients with moderate to very severe chronic obstructive pulmonary disease". Journal of Respiratory Medicine (2016): 1491-1501.

19. Reisner C., et al. "Pharmacokinetics and safety of a single dose of the novel LAMA/LABA fixed dose combination of glycopyrronium/formoterol fumarate dehydrate metered dose inhaler, formulated using co-suspension delivery technology, in Japanese healthy subjects". Pulmonary Pharmacology and Therapeutics 53 (2018): 33-38.
20. Onishi K . "Total management of chronic obstructive pulmonary disease (COPD) as an independent risk factor for cardiovascular disease". Journal of Cardiology 70 (2017): 128-134.

21. Zhao D., et al. "Efficacy and safety of tiotropium bromide combined with budesonide/formoterol in the treatment of moderate to severe chronic obstructive pulmonary disease". Experimental and Therapeutic Medicine 16 (2018): 4578-4584.

22. Chen W., et al. "Risk of cardiovascular co morbidity in patients with chronic obstructive pulmonary disease: a systematic review and meta-analysis". Lancet Respiratory Medicine (2015): 155-172.

23. Suissa S., et al. "Long-acting bronchodilator initiation in COPD and the risk of adverse cardio-pulmonary events: A population-based comparative safety study". Journal of CHEST (2016): 319-369.

24. Yee $\mathrm{K} \mathrm{C}$ and Knobloach J. “Cardiovascular safety of new inhaled medications for asthma and chronic obstructive pulmonary disease: a critical review from pharmacist perspective". International Journal of Research in Medical Sciences 4.6 (2016): 1814-1829.

25. Kumar A., et al. "Assessment of cardiovascular changes among chronic obstructive pulmonary disease patients at rural tertiary care center of Northern India". International Journal of Medical Science and Public Health 6.8 (2017): 1320-1324.

26. Gupta N K., et al. "Echocardiographic evaluation of heart in chronic obstructive pulmonary disease patient and its corelation with the severity of disease". Lung India 28.2 (2011): 105-109.

27. Materaet MG. "Safety Considerations with Dual Bronchodilator Therapy in COPD: An Update". Springer International Publishing Switzerland (2016): 259-267.

28. Smid D E., et al. "Impact of cardiovascular co morbidities on COPD Assessment Test (CAT) and its responsiveness to pulmonary rehabilitation in patients with moderate to very severe COPD: protocol of the Chance study". British Medical Journal 5 (2015): 122.

29. Hersh C P., et al. "Family History Is a Risk Factor for COPD". Journal of Chest 140.2 (2011): 343-350. 
30. Guillien A., et al. "Prevalence and risk factors for COPD in farmers: across-sectional controlled study". European Respiratory Journal 47 (2016): 95-103.

31. Byrd J B., et al. "Blood pressure, heart rate, and mortality in chronic obstructive pulmonary disease: the SUMMIT trial". European Heart Journal (2018): 1-7.

32. Kardos P and Peinz IH. "The impact of indacaterol/glycopyrronium fixed dose combination versus tiotropium monotherapy on lung function and treatment preference: a randomized crossover study - the Favor study". International Journal of COPD 13 (2018): 69-77.

33. Buhl R., et al. "Blinded 12-week comparison of once-daily indacaterol and tiotropium in COPD". Europian Respiratory Journal 38.4 (2011): 797-803.

34. Lehmann S., et al. "A randomized trial to determine the impact of indacaterol/glycopyrronium on nighttime oxygenation and symptoms in patients with moderate-to-severe COPD: the Duosleep study". International Journal of COPD 14 (2019): 199-210.

35. Abdulsalim S., et al. "Structured Pharmacist-led Intervention Programme to Improve Medication Adherence in COPD Patients: A randomized controlled study". European Respiratory Journal 10 (2018): 909-914.

36. Montes de Oca M., et al. "Adherence to inhaled therapies of COPD patients from seven Latin American countries: The LASSYC study". Journal Plose One (2017): 1-14.

37. Kim SH., et al. "Chronic obstructive pulmonary disease is independently associated with hypertension in men A survey design analysis using nationwide survey data". Journal of Medicine 96.19 (2017): 1-7.

\section{Assets from publication with us}

- Prompt Acknowledgement after receiving the article

- Thorough Double blinded peer review

- Rapid Publication

- Issue of Publication Certificate

- High visibility of your Published work

Website: https://www.actascientific.com/

Submit Article: https://www.actascientific.com/submission.php Email us: editor@actascientific.com

Contact us: +919182824667 